\title{
Implementation Strategies Used by States to Support Physical Activity Licensing Standards for Toddlers in Early Care and Education Settings: An Exploratory Qualitative Study
}

\author{
Laura Lessard, PhD, MPH,' Katherine E. Speirs, PhD, and Nicole Slesinger, MS'
}

\section{Abstract}

Background: Child care settings have been a target for childhood obesity prevention efforts; changing licensing standards to require physical activity (PA)-related best practices is one strategy being used by states. The mechanisms used to support implementation by providers remain understudied, despite the potential for these efforts to significantly impact child-level outcomes. This qualitative study explored the mechanisms used and any outstanding challenges to implementation experienced by US states with one specific best practice PA licensing standard for toddlers (60-90 min of PA/day).

Methods: All states with the selected PA licensing standard were invited to participate $(N=9)$. Interviews were conducted with the licensing administrator and others in the state involved with implementation and referred by the Administrator (e.g., Licensing Inspectors). A total of 20 individuals from seven states were interviewed. All interviews were recorded, professionally transcribed, and analyzed to identify themes.

Results: A range of strategies was reported, however the majority of interviewees reported that providers experienced few challenges with implementation. Steps taken during the rulemaking process and technical assistance provided by licensing staff, government and nonprofit partners were frequently mentioned as contributing to implementation success. Challenges faced by licensing staff included lack of resources and a need for specific, age-appropriate PA-promoting activities that providers could easily implement.

Conclusions: Based on the experience of participating states, other jurisdictions may want to explore adding PA-related requirements to their licensing standards. The lessons learned from these seven states may be helpful during the rulemaking and implementation processes.

Keywords: child care; early care and education; physical activity; toddlers; obesity prevention

\section{Introduction}

I mproving physical activity (PA) levels can help prevent childhood obesity, and US national guidelines suggest that children as young as 12 months should engage in 90 minutes of structured and unstructured PA per day. ${ }^{1-3}$ International guidelines recommend similar or higher levels of PA for young children; both the Australian and UK guidelines recommend 180 minutes of PA per day for toddlers aged 1-2 years. ${ }^{4,5}$ Establishing these healthy patterns early in life is crucial; a recent systematic review concluded that PA behaviors developed in early childhood (before 6 years of age) track both within that age group and into later childhood. ${ }^{6}$ Thus identifying ways to increase PA in young children is an important area of research and practice.

Early care and education (ECE) settings offer a promising venue in which to focus PA promotion efforts, as recent estimates suggest that $76 \%$ of children in the United States aged 3-5 years have at least one weekly, nonparental child care arrangement. ${ }^{7}$ One intervention strategy involves changing licensing standards to require certain

'Department of Behavioral Health and Nutrition, University of Delaware, Newark, DE.

${ }^{2}$ Norton School of Family and Consumer Sciences, University of Arizona, Tucson, AZ. 
best practices related to nutrition, $\mathrm{PA}$, and screen time. For example, states can require that licensed ECE providers offer twice daily outdoor play, weather permitting, or 60 90 minutes of PA for preschoolers that is consistent with recommendations. ${ }^{8}$ Integrating these standards into licensing can promote health equity by improving the ECE environment for all children in group care, not just those attending high-cost facilities. In recognition of this opportunity, the Institute of Medicine, ${ }^{9}$ The Society of Behavioral Medicine, ${ }^{10}$ and US Centers for Disease Control and Prevention $(\mathrm{CDC})^{11}$ include policy-level interventions targeting changes in the ECE environment as priorities for reducing obesity in young children. A recent CDC report found that 25 states have implemented licensing regulations that include obesity prevention in some manner since $2011 .{ }^{11}$ Preliminary evidence from New York City, ${ }^{12}$ and South Carolina ${ }^{13}$ suggests that, if implemented at the provider level, these policies can result in improvements in health (e.g., PA and healthy food consumption) at the child level. A study from Alberta, Canada found improvements in PA for toddlers, but not preschoolers, after changes to accreditation standards. ${ }^{14}$

Although adding best practices related to obesity prevention to ECE licensing standards is a first step toward reducing obesity in this population, the implementation of these policies is also required for an impact to be realized at the child level. Previous research has suggested that compliance with these policies can vary significantly depending on the measures used and support provided. One study of compliance with California's healthy beverage policy for child care sites found that only $23 \%$ of respondents were fully compliant with the law ${ }^{15}$; a study of providers in Delaware found that only $21 \%$ could correctly identify the licensing standards related to PA. ${ }^{16}$

Given these challenges to full implementation, jurisdictions have used a number of mechanisms to increase understanding and implementation of these policies by providers. A recent Cochrane Review ${ }^{17}$ identified six categories of strategies that have been used to support changes in child care settings: educational materials, educational meetings (including workshops), educational outreach visits or academic detailing, small incentives or grants, audit and feedback, and opinion leaders (e.g., learning collaboratives). However, there is limited evidence of the use and impact of these mechanisms that is crucial to expanding the implementation and therefore the impact of these licensing policies on children's health. The review concluded that, "formative work to achieve a comprehensive understanding of the setting, context and barriers to implementation" should be undertaken. ${ }^{17}$

The purpose of this qualitative study was to explore implementation support provided by states that have a model PA-related licensing standard: 60-90 $\mathrm{min}$ of PA/day for toddlers (aged 1-3 years). The aims of the research were to identify (1) the mechanisms used by jurisdictions to implement and enforce the regulation and (2) any outstanding challenges to implementation reported by individuals involved in licensing and/or implementation at the state level.

\section{Methods}

Purposive sampling was used to recruit participants from states that have one model PA regulation for toddlers in child care. One specific standard was chosen so that interviewees could more accurately describe the support offered to providers; toddler PA was chosen because although it is listed as a best practice for child care settings, a small number of states (nine) have included it within their licensing standards. Semistructured interviews were conducted with participants that were audio recorded, transcribed, and analyzed to address the research aims.

\section{Sampling}

Two levels of sampling were used to select participants for the study, with the goal of understanding the supports that are available for implementation through or in conjunction with licensing at the state level. First, states were selected from the results of a recently conducted review of state licensing regulations that was conducted by the Public Health Law Center (PHLC) with Robert Wood Johnson Foundation funding. ${ }^{18}$ All nine states that were identified by PHLC as having licensing regulations requiring 60-90 minutes of PA for toddlers in full-time care were included in the initial sample. At the participant level, modified snowball sampling was used. For each of the nine states, the state licensing administrator was identified by reviewing the most recent Child Care and Development Fund (CCDF) plans available through the federal Office of Child Care within the Office of the Administration for Children and Families (ACF). The administrators were contacted through email and/or phone and invited to participate in an interview on their state's licensing rule related to PA for toddlers. During the interviews, participants were asked to identify others within their state who might be appropriate for interviews including those involved in the communication, enforcement, and/or support of the PA regulation (usually through training and technical assistance). These individuals (e.g., staff members from nonprofit training partners, licensing inspectors) were then approached via email and/or phone and invited to participate in an interview. Although no child care providers were interviewed, all interviewees were asked to comment on provider-level challenges. All participants were offered an Amazon gift card as an incentive, although the majority were not able to accept the incentive because of regulations within their state that restrict public officials from accepting gifts.

\section{Interview Guide}

A semistructured interview guide was developed by the research team to address the research aims. Interviews began by asking respondents to describe their role within the child care system and their involvement with the initial development of the licensing standard. The following section asked about communication about the regulations to ascertain how the regulations were initially rolled out within each state (e.g., How did you let providers know about the 
change in regulations? Which of these strategies do you think were the most successful?). The next section covered a wide range of implementation strategies that the state might have used to support providers, including training or technical assistance. For each strategy mentioned, follow-up questions were asked regarding target audience, strengths, and weaknesses. The next section covered current barriers to implementation and enforcement. The last section specifically asked for recommendations for other states that may be considering adding this component to their licensing standards. The interview guide was slightly altered for different respondents. For example, some respondents were responsible for specific programmatic components of a state's implementation support strategy (e.g., community-based training for providers). These respondents were asked more in-depth questions about their component, and slightly more general questions within the other domains. Interviews lasted between 15 and 60 minutes.

\section{Data Management and Analysis}

With permission, all interviews were audio recorded and professionally transcribed verbatim. The resulting transcripts were reviewed by the research team for accuracy. Focused, thematic analysis involving both deductive and inductive coding was used to address the research aims. A preliminary list of codes was generated by the research team (deductive coding) based on an initial review of the literature, data, and the research aims. Additional inductive codes were added during the coding process. Interrater reliability was established by two coders (L.L. and K.S.) coding four of the transcripts ( $\sim 27 \%$ of the data). Discrepancies were resolved during discussion between the two coders until consensus was achieved. The remaining transcripts were coded by one coder and then reviewed by the other coder. The second coder noted any disagreements with the first coder's application of the codes and then the two coders discussed and resolved these discrepancies.

Themes were generated during an iterative process in which the first two authors used the coding to write preliminary themes. They then moved between discussions of the themes, returning to the data to confirm the themes, and writing about and revising the themes until they had agreed on a final set of themes. Data analysis was organized using the computer program Dedoose (version 7.5.9, 2018, SocioCultural Research Consultants, LLC).

All study procedures were given Expedited Review and subsequently approved by the Institutional Review Board of the University of Delaware (FWA \#00004379). All interviewees provided informed consent to participate.

\section{Results}

Seven of the nine states included in the initial sample participated in the study. Of the remaining two states, one state administrator declined participation and an administrator from the ninth state could not be reached. Table 1 provides the list of states included in the sample along with the full text of their relevant licensing standard. The total number of individuals interviewed from each state ranged from 1 to 4, and a total of 20 individuals were interviewed.

Most states reported few serious challenges in implementation of the PA rule, and many indicated that providers were supportive of the change or were already voluntarily providing at least 60 minutes of PA to toddlers in their care. One licensing administrator explained that:

[the PA regulation for toddlers] is not one of our frequent fliers for violation. People have really been pretty good about incorporating this. It's not on our radar as them having difficulties. And actually we've heard a lot from programs that it was pretty easy to incorporate.

One licensing administrator for another state agreed, "From a provider's standpoint I've not heard anything negative about it. Actually, they like it, I think. I mean, that's my understanding just getting the kids up and doing activities to get them moving. It's all been positive."

\section{Mechanisms Reported by States}

Although the mechanisms reported by states varied across the seven jurisdictions, common themes across states included the following: (1) steps taken during the rulemaking process, (2) linkages between licensing and other governmental or nonprofit partners, and (3) inspections conducted as a routine part of licensing.

Many states described steps taken during the rulemaking process that were designed to support implementation, including writing clear rules that are easy for providers to understand and engaging stakeholders.

The language used in the rule itself is one mechanism used by states to support implementation. Several states mentioned that making the number of minutes of PA explicit removed the ambiguity of former regulations that did not include a minimum number of minutes. In addition, one licensing administrator suggested that other states considering this standard, "learn from [their] mistakes, ensuring that all the requirements are measurable." In particular, respondents identified three areas that should be clearly articulated in the licensing regulations: how many minutes of PA are required each day (which may be different for part-time vs. full-time care), where the PA should be performed (inside or outside), and a description of the kind or quality of PA that is expected (e.g., specifying moderate to vigorous activity).

All states described engaging providers to build buy-in during the rulemaking process as one of the keys to subsequent success with implementation. This engagement generally involved both providers and the advocacy community within states. One staff from a nonprofit training partner explained the benefits:

...usually if you can explain why you want the change that you want, [the provider community] can understand. I think having a good mix on a taskforce, having a good mix on the advisory councils is important, because you do get to see other sides and everyone gets to see other sides. 


\section{Table I. Participating States and their Physical Activity Licensing Standard}

\begin{tabular}{|c|c|}
\hline $\begin{array}{l}\text { State name* } \\
\text { (number of } \\
\text { interviewees) }\end{array}$ & Relevant licensing language \\
\hline \multirow[t]{2}{*}{$\mathrm{CO}(3)^{1}$} & $\begin{array}{l}\text { Daily physical gross motor activities, with or without equipment or materials, must be provided to toddler age children } \\
\text { outdoors for no less than fifteen (I5) minutes for part day programs operating up to three ( } 3 \text { ) hours per day, no less than } \\
\text { thirty ( } 30 \text { ) minutes total for part day programs operating from three (3) to five (5) hours per day, and no less than sixty (60) } \\
\text { minutes for full day programs. }\end{array}$ \\
\hline & $\begin{array}{l}\text { When inclement weather limits outdoor activities, indoor physical daily gross motor activities, with or without equipment } \\
\text { or materials, must be provided to toddler age children outdoors for no less than fifteen (I5) minutes for part day } \\
\text { programs operating up to three ( } 3 \text { ) hours per day, no less than thirty (30) minutes total for part day programs operating } \\
\text { from three (3) to five (5) hours per day, and no less than sixty (60) minutes for full day programs. }\end{array}$ \\
\hline \multirow[t]{2}{*}{$\mathrm{KS}(3)^{2}$} & $\begin{array}{l}\text { Each child shall be given the opportunity for at least one hour of physical activity daily, either outdoors as described in } \\
\text { paragraph (a)(7) or indoors. }\end{array}$ \\
\hline & $\begin{array}{l}\text { Unless prohibited by the child's medical condition or extreme weather conditions, each child in care shall be taken } \\
\text { outdoors daily. Each child } 12 \text { months of age or older shall have the opportunity for at least one hour of outdoor play daily. }\end{array}$ \\
\hline LA (4)' & $\begin{array}{l}\text { Children age two and older shall be provided a minimum of } 60 \text { minutes of physical activity per day that includes a } \\
\text { combination of both teacher led and free play. }\end{array}$ \\
\hline$M S(3)^{1,2}$ & $\begin{array}{l}\text { Toddlers should accumulate a minimum of } 60 \text { minutes of structured moderate to vigorous physical activity per day. } \\
\text { Examples of "moderate physical activity" are aerobic dancing, light calisthenics, getting up and down from the floor, } \\
\text { dancing, playing on school ground equipment, singing while actively moving about, etc. Examples of "vigorous physical } \\
\text { activity" are running, jumping rope, performing jumping jacks, playing soccer, skipping, etc. Regardless of the activity, it } \\
\text { should be age appropriate and within the physical ability limits of the child. Please, understand the above requirement does } \\
\text { not mean } 60 \text { minutes vigorous activity at one time. The } 60 \text { minutes of vigorous physical activity can and should be spread } \\
\text { out in short time intervals, (e.g., } 5 \text { - I5 minute intervals) throughout the day. }\end{array}$ \\
\hline NM (4) ${ }^{\prime}$ & $\begin{array}{l}\text { Full-time children shall have a minimum of } 60 \text { minutes of physical activity daily, preferably outside. Part-time children shall } \\
\text { have a minimum of } 30 \text { minutes of physical activity daily, preferably outside. }\end{array}$ \\
\hline $\mathrm{RI}(2)^{1,2}$ & $\begin{array}{l}\text { Children ages twelve months or older attending a full-day program participate in at least sixty minutes of physical activity } \\
\text { per day. Children attending less than a full-day program participate in a proportionate amount of physically active play. Staff } \\
\text { promote children's active play and participate with children when physically able to do so for at least an hour each day. }\end{array}$ \\
\hline \multirow[t]{2}{*}{ WV $(I)^{\prime}$} & $\begin{array}{l}\text { [Activities must include] A minimum of sixty }(60) \text { minutes of moderate to vigorous activity per eight-hour }(8) \text { day } \\
\text { for toddlers and children up to three (3) years; A minimum of ninety }(90) \text { minutes of moderate to vigorous activity per } \\
\text { eight-hour (8) day for children three (3) years to school age; }\end{array}$ \\
\hline & $\begin{array}{l}\text { Moderate to Vigorous Physical Activity. -- Levels of activity that are conducted at varying intensities. Moderate physical } \\
\text { activity is faster than a slow walk, but still allows children to talk easily. It increases the heart rate and breathing rate. } \\
\text { Vigorous physical activity is rhythmic, repetitive physical movement that uses large muscle groups, causing children to } \\
\text { breathe rapidly and only enabling them to speak in short phrases. Typically children's heart rates are substantially increased } \\
\text { and they are likely to be sweating. Toddlers and preschoolers generally accumulate vigorous physical activity over the } \\
\text { course of the day in very short bursts, usually fifteen (I5) to thirty (30) seconds. }\end{array}$ \\
\hline
\end{tabular}

'Licensing standard applies to child care centers.

${ }^{2}$ Licensing standard applies to family child care homes.

CO, Colorado; KS, Kansas; LA, Louisiana; MS, Mississippi; NM, New Mexico; RI, Rhode Island; WV, West Virginia.

The venues for this engagement ranged from ongoing advisory boards to formal hearings to more informal listening sessions conducted in person or through conference call to online feedback surveys. One licensing administrator suggested that other states:

Sit down with all the partners within your state that have a vested interest in what you're trying to do. Sometimes you have to make compromises because programs are gonna have a different idea of what will work for them than what maybe the healthcare advocates would like to see, but you can come to a compromise on a best rule package that kinda fits for all.

Every interviewee discussed some component of linkages between the licensing agency and other governmental or nonprofit partners. For some, these linkages were carefully coordinated and afforded providers access to training that the licensing agency would not have the resources or expertise to provide. For example, licensing staff in Rhode Island specifically link providers with the resources available at one of their nonprofit partners, including intensive technical assistance and a mini-grant program focused on playground safety. This successful coordination was apparent in states where the licensing agency sat within the department of health (e.g., Colorado), where intergovernmental task forces were called to develop or revise standards, and/or in states where the administrator himself or herself was passionate about 
health issues. In contrast, there seemed to be several missed opportunities to better link provider needs with existing resources. In multiple states, licensing staff were unaware of specific training materials or resources that were available in their state or those that were available were not linked with the PA requirements in the licensing standard (i.e., promoted a different number of minutes of PA per day, usually in excess of the licensing requirement).

Inspections conducted as a routine component of licensing were the most frequently mentioned avenue for assessing compliance and providing technical assistance across states in our sample. In some states, if challenges with the PA regulation were identified during inspections, the providers were referred to additional resources provided by licensing or partner agencies. These resources also sometimes included one-on-one support; according to one nonprofit partner,

\footnotetext{
Where we've had the most success in terms of really changing practice, that's through our intensive on-site technical assistance. You know, really working with people over a sustained period of time, physically being with them at their centers, and really helping them problem solve around their specific needs. I don't think there's any question that that's where we see real changes happening.
}

In two states, "soft roll out" periods were used to allow licensing staff to explain the rule changes to providers and address any challenges providers were facing in implementing the rule before enforcement penalties were in place. The licensing staff thought that this changed the dynamics between their office and the providers that may ultimately increase compliance. According to one licensing inspector:

We want them to be in compliance and they want to be in compliance because that's what's best for kids. And so if we work as partners and they don't see us so much as right [from] the get-go coming out and being the enforcer, we feel like it's worked very well and we've seen not as much pushback when we roll out new rules.

In contrast, there seems to be a need to increase the knowledge and skill levels of the inspectors so that they can be better prepared to support providers who are struggling with the PA regulation. In many states the licensing inspectors were not given training themselves on how to support providers who were not meeting the PA standard.

Other mechanisms mentioned were less common across states, but included newsletters sent through mail and/or email and printed copies of the regulations and/or implementation guides sent to providers linking to existing web-based resources provided by health departments and other nonprofit partners and mini-grants to improve the quality of playgrounds and/or the availability of play equipment. In few cases did the interviewees have information about the effectiveness of these support mechanisms.

\section{Challenges to Implementation}

Results indicated two categories of challenges related to implementation: those faced by licensing staff in providing training and technical assistance to providers and those faced by providers in offering opportunities for PA to the children in their care.
Licensing staff faced challenges reaching providers located in rural areas, especially in large states, and those who did not have access to or were not familiar with technology. Most of the states had embraced online training and were using email to communicate with providers. However, they acknowledged the drawbacks to this approach. One director of a state agency stated: "I probably don't catch everyone, because they do everything now by email. Not everyone checks their email. Not everyone has access to email, because we are such a rural state." However, in large states with limited budgets and licensing staff, in-person training and technical assistance was not always possible.

Interviewees in many of the states also noted that high rates of turnover among licensing specialists and high caseloads for specialists complicated implementation. A nonprofit partner noted:

\footnotetext{
Our budget is being eviscerated every year. Our agenciesthey're being asked to do more with less ... They can't keep people on staff because they're underpaid ... there's so much turnover, you don't get a lot of long-term wisdom. The wisdom walks out the door every few years because they've got to go find another paying job.
}

In addition to challenges faced by licensing staff, interviewees identified two areas where they perceived that providers often need additional support to provide highquality PA experiences for the children in their care. First, providers benefited from training and technical assistance in how to create and maintain safe indoor and outdoor spaces for PA. One nonprofit partner explained:

\footnotetext{
One initial barrier is that very few centers have a dedicated indoor gross motor area, and very few centers have generous enough square footage in the classrooms or the buildings that they can even temporarily dedicate spaces for indoor gross motor activities. So, that can be very limiting if they're not going outside. Moving to the outside area, in some but not all cases, the spaces are fairly small...We have also discovered a number of safety issues on the play spaces here.
}

Second, interviewees reported that providers often needed examples of activities that would keep children engaged in PA. One nonprofit partner explained that in general she did not find providers were interested in complying with PA regulations. However "after (she goes) out and model(s) these great, fun activities that (her agency) has developed...the teachers do get excited about it because these games are fun, and they're also teaching a concept... After that... a lightbulb goes off."

Although interviewees in states with temperate climates mentioned that the weather aided implementation, most reported that extreme weather presented a third challenge to providers. One interviewee explained:

\footnotetext{
In areas where there's snow on the ground or it's a little colder, it might be harder for the physical activities because it's a lot easier to throw the kids outside for 30 minutes or an hour than it is to try to find stuff to do inside.
}

Some states provided guidance about when children should and should not be outside (e.g., children should go 
outside when the temperature was between $40^{\circ}$ and $80^{\circ}$ ) to address this challenge.

\section{Discussion}

This study used semistructured interviews with 20 child care state licensing administrators and other professionals involved with implementation at the state level from seven states to identify the mechanisms used to implement model PA licensing regulations and implementation challenges. In general respondents reported that implementation of regulations requiring 60-90 minutes of PA per day was relatively easy and offered several strategies that they found effective.

Interviewees reported the importance of clearly stated licensing laws, ensuring provider buy-in during the rulemaking phase, and working with government and nonprofit partners to provide training and technical assistance. The importance of training and technical assistance for ensuring compliance with PA regulations has been noted elsewhere. A multicomponent training program offered by the New York City Department of Health and Mental Hygiene was linked to better compliance with PA regulations requiring at least 60 minutes of PA per day. ${ }^{19}$ In Minnesota, participation in a training and support program for child care centers and homes was linked with a greater likelihood of implementing a PA policy for the center. ${ }^{20}$

These results suggest the importance of training and technical assistance and collaboration between public health professionals and the licensing community to deliver these supports. Although coordination across agencies seemed to be a successful mechanism used by many states, there were opportunities to improve these efforts. Organizations involved in training providers on PA-related topics may want to familiarize themselves with their state's licensing standards and ensure that their training aligns.

In terms of challenges to implementation, our interviewees cited a lack of provider knowledge about the kinds of activities that promote PA for young children and inadequate resources to provide safe spaces for PA. These findings mirror those from studies examining provider perspectives on barriers to promoting PA in child care settings. In a focus group study $(n=54)$, providers from London, Ontario reported needing training in how to lead PA sessions and suggestions for activities that promote PA as well as additional funds to purchase sports and playgroup equipment and create spaces for PA. ${ }^{21}$ A study of 30 family day care providers in Rhode Island also found that concerns about child safety in indoor play spaces were a barrier to providers engaging the children in PA. ${ }^{22}$

However, there is conflicting evidence concerning a direct link between providers' knowledge about how to promote PA and environmental elements (e.g., space and equipment for PA) and levels of child PA. A crosssectional analysis of 174 child care centers in New York City found a positive association between centers having an outdoor play space and provider-reported levels of child PA. ${ }^{19}$ However, using a sample of 388 children from 30 randomly selected child care centers in Cincinnati, $\mathrm{OH}$, Copeland et al. found that none of the following were associated with accelerometer-measured moderate to vigorous PA for preschoolers: the availability of portable indoor or outdoor play equipment, indoor or outdoor play space, and PA training for providers. ${ }^{23}$ Taken together these results suggest that more work is needed to tease apart exactly which environmental elements, training, and provider knowledge are likely to result in children meeting the recommended amounts of daily moderate to vigorous PA.

As with all policy-related research, the state-specific context was a significant subtheme within our data. For example, although this study focused on changes to licensing specifically, providers are generally subject to several sets of rules and regulations, some they can choose to comply with (e.g., quality rating systems) and others that carry severe penalties for noncompliance. Licensing standards are not the only policy lever that can be used to change provider practice but are probably best used in conjunction with other efforts. As one licensing administrator mentioned, "[Licensing] regulations are the foundation ... Sometimes they may look like quality standards, but they should really be the point that the majority of the regulated community should be able to obtain and maintain."

Finally, future work should consider implementation adherence. ${ }^{6}$ It is important to develop systems that allow licensing staff to accurately determine the amount of PA children engage in. Often licensing staff rely on provider reports of the amount of time scheduled for PA. However, there is evidence that these provider reports overestimate the amount of time children are physically active. ${ }^{23}$

\section{Limitations}

Although this study focused on one PA component, all but one of the states reported that the addition of this component was part of a broader revision of licensing regulations that happens on a set schedule (e.g., every 3 or 5 years). Thus the PA component would be just one change among many that might need training, technical assistance, and support to be fully implemented. During the interviews, several licensing administrators had difficulty separating their efforts to educate the provider community about this piece from larger efforts to rollout licensing changes. This may have caused them to underreport the support that was made available, especially around the time of the initial change.

In addition, licensing administrators and their partners were the target for this study, therefore we are not able to report providers' perspectives, but future research would benefit from including them. In particular, our discussion of successful implementation mechanisms and challenges stems from the licensing administrators' perspectives. We do not know whether providers may have identified different or additional mechanisms that aided implementation or challenges, although our findings are in line with findings from the few studies that report provider perspectives. In addition, licensing administrators have a unique perspective 
in that they designed the strategies and mechanisms that were the focus of this study, which should be considered in interpreting our results.

\section{Conclusions}

This article serves as a useful guide for state child care licensing administrators as they work to ensure that their licensing standards match best practices. Our analysis of interview data with individuals from seven states provides insights into how PA-related licensing standards can be used to promote health and well-being and prevent childhood obesity. In particular, our findings suggest that licensing standards should be carefully and specifically written to aid in implementation and enforcement, coordinated efforts with other government offices and nonprofit partners can ensure the provision of useful and timely training and technical assistance, and licensing administrators should prepare for and be ready to address resource and knowledge limitations in their own offices and among providers.

\section{Acknowledgments}

The authors thank Julie Shuell and Anna Ayers-Looby for their support in conceptualizing this study and the many participants who shared their time and experience with us during interviews.

\section{Author Disclosure Statement}

No competing financial interests exist.

\section{References}

1. Remmers T, Sleddens EF, Gubbels JS, et al. Relationship between physical activity and the development of body mass index in children. Med Sci Sports Exerc 2014;46:177-184.

2. Shape America. A Statement of Physical Activity Guidelines for Children from Birth to Age 5. Society of Health and Physical Educators: Reston, VA, 2009.

3. 2018 Physical Activity Guidelines Advisory Committee. 2018 Physical Activity Guidelines Advisory Committee Scientific Report. U.S. Department of Health and Human Services: Washington, DC, 2018.

4. Australian Government Department of Health, Population Health Division. Australia's Physical Activity and Sedentary Behaviour Guidelines. Australian Government Department of Health, Canberra, Australia, 2014.

5. Bull FC, and the Expert Working Groups. Physical Activity Guidelines in the U.K.: Review and Recommendations. School of Sport, Exercise and Health Sciences. Loughborough University, Loughborough, England, 2010.

6. Jones RA, Hinkley T, Okely AD, et al. Tracking physical activity and sedentary behavior in childhood: A systematic review. $\mathrm{Am} \mathrm{J}$ Prev Med 2013;44:651-658.

7. Mamedova S, Redford J. Early Childhood Program Participation, From the National Household Education Surveys Program of 2012 (NCES 2013-029. REV). National Center for Education Statistics, Institute of Education Sciences, U.S. Department of Education: Washington, DC, 2012.
8. National Resource Center for Health and Safety in Child Care and Early Education. Achieving a State of Healthy Weight: 2015 Update. National Resource Center for Health and Safety in Child Care and Early Education: Aurora, CO, 2016.

9. Institute of Medicine. Early Childhood Obesity Prevention Policies: Goals, Recommendations and Potential Actions. National Academy of Sciences, Washington, DC, 2011.

10. Buscemi J, Kanwischer K, Becker A, et al. Society of Behavioral Medicine position statement: Early care and education (ECE) policies can impact obesity prevention among preschool-aged children. Transl Behav Med 2015;5:122-125.

11. Centers for Disease Control and Prevention. Early Care and Education State Indicator Report. Atlanta, GA, 2016.

12. Stephens RL, Xu Y, Lesesne CA, et al. Relationship between child care centers' compliance with physical activity regulations and children's physical activity, New York City, 2010. Prev Chronic Dis 2014;11:E179.

13. O'neill J, Dowda M, Benjamin Neelon S, et al. Effects of a new state policy on physical activity practices in child care centers in South Carolina. Am J Public Health 2017;107:144-146.

14. Carson V, Clark D, Ogden N, et al. Short-term influence of revised provincial accreditation standards on physical activity, sedentary behavior, and weight status in Alberta, Canada child care centers. Childhood Educ J 2015;43:459-465.

15. Ritchie L, Sharma S, Gildengorin G, at al. Policy improves what beverages are served to young children in child care. J Acad Nutr Diet 2015;115:724-730.

16. Van Stan S, Lessard L, Dupont Phillips K. The impact of a statewide training to increase child care providers' knowledge of nutrition and physical activity rules in Delaware. Child Obes 2013;9:43-50.

17. Wolfenden L, Jones J, Williams C, et al. Strategies to improve the implementation of healthy eating, physical activity and obesity prevention policies, practices or programmes within childcare services. Cochrane Database Syst Rev 2016;10:CD011779.

18. Healthy Eating, Active Play, Screen Time: Best Practices (web resource). Available at www.publichealthlawcenter.org/heal/ ChildCareMaps.html Last accessed February 16, 2018.

19. Kakietek J, Dunn L, O'dell S, et al. Training and technical assistance for compliance with beverage and physical activity components of New York City's regulations for early child care centers. Prev Chronic Dis 2014;11:E177.

20. Pelletier J, Hassan A, Zukoski A, et al. Public health support for weight-related practices in child care settings in Minnesota. Health Promot Pract 2018:1524839918781523.

21. Tucker P, An Zandvoort M, Burke S, et al. Physical activity at daycare: Childcare providers' perspectives for improvements. $J$ Early Childhood Res 2011;9:207-219.

22. Tovar A, Mena N, Risica P, et al. Nutrition and physical activity environments of home-based child care: What hispanic providers have to say. Child Obes 2015;11:521-529.

23. Copeland K, Khoury J, Kalkwarf H. Child Care Center characteristics associated with preschoolers' physical activity. Am J Prev Med 2016;50:470-479.

Address correspondence to:

Laura Lessard, PhD, MPH

Department of Behavioral Health and Nutrition

University of Delaware

Carpenter Sports Building

Newark, DE 19716

E-mail:1lessard@udel.edu 